FEDERAL RESERVE BANK OF SAN FRANCISCO

WORKING PAPER SERIES

\title{
Pegged Exchange Rate Regimes - A Trap?
}

\author{
Joshua Aizenman \\ University of California, Santa Cruz \\ and \\ Reuven Glick \\ Federal Reserve Bank of San Francisco
}

September 2005

Working Paper 2006-07

http://www.frbsf.org/publications/economics/papers/2006/wp06-07bk.pdf

The views in this paper are solely the responsibility of the authors and should not be interpreted as reflecting the views of the Federal Reserve Bank of San Francisco or the Board of Governors of the Federal Reserve System. This paper was produced under the auspices for the Center for Pacific Basin Studies within the Economic Research Department of the Federal Reserve Bank of San Francisco. 


\title{
Pegged Exchange Rate Regimes - A Trap?*
}

\author{
Joshua Aizenman and Reuven Glick
}

September, 2005

\begin{abstract}
:
This paper studies the empirical and theoretical association between the duration of a pegged exchange rate and the cost experienced upon exiting the regime. We confirm empirically that exits from pegged exchange rate regimes during the past two decades have often been accompanied by crises, the cost of which increases with the duration of the peg before the crisis. We explain these observations in a framework in which the exchange rate peg is used as a commitment mechanism to achieve inflation stability, but multiple equilibria are possible. We show that there are ex ante large gains from choosing a more conservative not only in order to mitigate the inflation bias from the well-known time inconsistency problem, but also to steer the economy away from the high inflation equilibria. These gains, however, come at a cost in the form of the monetary authority's lesser responsiveness to output shocks. In these circumstances, using a pegged exchange rate as an anti-inflation commitment device can create a "trap" whereby the regime initially confers gains in anti-inflation credibility, but ultimately results in an exit occasioned by a big enough adverse real shock that creates large welfare losses to the economy. We also show that the more conservative is the regime in place and the larger is the cost of regime change, the longer will be the average spell of the fixed exchange rate regime, and the greater the output contraction at the time of a regime change.
\end{abstract}

Joshua Aizenman

Department of Economics

University of California, Santa Cruz

jaizen@ucsc.edu
Reuven Glick

Economic Research Department

Federal Reserve Bank of San Francisco

reuven.glick@sf.frb.org

JEL Classification: F15, F31, F43

Keywords: Pegged exchange rate, duration, crises, credibility, discretion, monetary regime change

\footnotetext{
"We thank Jessica Wesley for research assistance. The views presented in this paper are those of the authors alone and do not necessarily reflect those of the NBER, the Federal Reserve Bank of San Francisco or the Board of Governors of the Federal Reserve System.
} 


\section{Introduction}

Exits from pegged exchange rate regimes have often been accompanied by crises and severe declines in economic activity. Major currency crises over the past decade have had particularly adverse effects on output growth; for example, output declined by 6\% in Mexico in 1995, 7\% in Thailand and Korea in 1998, and by more than 11\% in Argentina in 2002. Eichengreen (1999), documenting the absence of an exit strategy from fixed exchange rates for many countries, concludes: “...exits from pegged exchange rates have not occurred under favorable circumstances. They have not had happy results.”

This paper provides an explanation for why pegged exchange rate regimes have tended to end so explosively. It argues that using pegged exchange rate as a commitment device for achieving inflation stability can create a "trap" whereby the regime initially confers gains in anti-inflation credibility, but ultimately results in an exit occasioned by large adverse real shocks, resulting in big welfare losses to the economy. We thus suggest that fixed exchange rate regimes can plant the seeds of their own demise.

We do so in a framework extending Obstfeld (1996)'s setting, where the monetary authority determines the exchange rate (and hence the inflation rate) based on its the degree of aversion to inflation relative to output fluctuations, the magnitude of shocks, and the (fixed) cost of allowing discrete exchange rate changes. Specifically, we assume that the monetary authority is chosen from a pool of possible candidates/regimes, each differing in its degree of anti-inflation firmness.

In accordance with Rogoff (1985)'s insight, we find that the optimal monetary authority candidate is characterized by a "conservative bias", i.e. a relative weight on inflation stabilization greater than that of society as a whole, in order to mitigate the inflation bias arising from time inconsistency. However, in our framework we also show that multiple equilibria are possible. In this case there are ex ante gains from choosing a more conservative monetary authority not only in order to lower private sector inflation expectations and mitigate the inflation bias, but also to steer the economy away from high inflation equilibria. These gains, however, come at a cost in the form of the monetary authority's lesser responsiveness to output shocks. Hence in choosing the monetary authority there is a tradeoff between, on the 
one hand, the gains from greater firmness in stabilizing inflation and, on the other hand, the ex post costs associated with a lesser willingness to respond to real shocks to the economy.

This tradeoff may plant the seeds of the regime's ultimate demise: bad enough shocks ultimately lead to the costly collapse of the regime. This result follows from the observation that large negative output shocks not resulting in devaluation will induce welfare losses to the public. In these circumstances, the gap in welfare evaluation between the public and monetary authority is of a first-order magnitude, proportional to the difference between the public's and the monetary authority's degree of firmness. Ultimately, for a bad enough shock, the cost of sustaining the existing regime will rise above the cost of regime change, inducing a large devaluation accompanied by sizable disruption of the economy. This suggests that more conservative and longer-lasting pegged regimes are likely to end with severe output losses. That is, the longer the duration of a peg before its collapse, the greater is the adverse effect on the economy when it does collapse. ${ }^{1}$

These results may explain the severity of the demise of an Argentinean type of currency board: legally anchoring the currency board in the constitution increased the cost of devaluation and regime change, but also planted the seeds of a trap associated with the fixed exchange rate regime. While in the short run it led to obvious credibility gains, it also increased the duration of the peg as well as the output costs associated with the devaluation that occurred when Argentina ultimately exited from the regime.

There is a vast literature on why pegged regimes may be crisis prone, dealing with issues that are well beyond the scope of the present paper. Some focus on how limiting exchange rate flexibility may increase risk taking by borrowers and lenders. Others focus on how liberalization and increased capital mobility have increased exposure to shocks, particularly those creating inconsistencies between a currency peg and other macroeconomic policies (see Agenor and Montiel (1999) and Obstfeld and Rogoff (1996) for further details). Our study is more closely related to papers that have studied the impact of policy maker preferences on the conduct of discretionary policy (see Cukierman and Liviatan (1991), Lohman (1992), and the references therein).

$1 \quad$ Klein and Marion (1997) analyze the duration of exchange rate regimes in Latin America. Husain, Mody and Rogoff (2005) study exchange rate regime durability and performance in developing versus advanced economies. 
Section 2 presents some stylized facts about the severity of output declines during recent exits from pegged regimes. In section 3 the theoretical model is presented. Section 4 concludes.

\section{Simple Stylized Facts about Exits}

To examine the decline in economic activity associated with exits to more flexible exchange rate regimes we make use of the data set assembled by Detragiache, Mody, and Okada (2005). They identify 63 episodes over the period 1980-2001 in which countries with heavily managed exchange rates ended in an exit, defined as a move to a more flexible exchange rate regime. ${ }^{2}$ Of these 63 episodes, 32 are deemed "disorderly” in the sense that currency fell freely at some time during the 12 month period after the exit; the remaining episodes are deemed “orderly”.

The top panel of Figure 1 presents event windows for the full sample of episodes showing the average behavior of real GDP growth for the years before, during, and after exits from pegged regimes, with the observations surrounded by two standard deviation bands. ${ }^{3}$ The figure shows that economic growth typically slows in the periods leading up the exit, is almost zero on average in the year after the exit occurs, following which growth recovers. For the subsample of disorderly exits in the bottom panel, the depth of the downturn is more severe and growth is actually negative in the year after exits. Figure 2 presents event windows for the more recent period of 1990-2001. Comparison with Figure 1 indicates that the severity of output declines is higher in the more recent period, supporting the view that greater capital mobility has increased the magnitude of welfare losses associated with financial crises.

Figure 3 presents scatter plots for GDP growth in either the year of an exit or the year after (whichever is lower) against the duration (in months) of the regime in place prior to the exit. For the full sample, a slight negative slope is apparent: the longer the duration of a pegged

2 More specifically, using the Reinhart-Rogoff "natural” classification scheme, they define an exit as occurring when a country moves from categories $1-2$, corresponding to pegs or heavily managed exchange rate regimes, to coarse categories 3-6, corresponding to more flexible regimes. A disorderly exit is characterized as one in which the transition is to the "freely falling" category, within 12 months of the original exit. Reinhart and Rogoff (2004) define the exchange rate as freely falling if its rate of depreciation is large, there is high inflation, or a speculative attack against the currency takes place. Note that the sample of Detragiache et al (2005) includes both developing and industrial countries.

3 We omit Iraq's 1982 exit because of the extreme decline in output, almost 40 percent. Note Detragiache et al treat this episode as an orderly exit. 
exchange rate regime, the lower (greater) is output growth (decline). When focus is drawn to the disorderly cases (bottom panel), the negative slope is more pronounced and is significant.

These results are confirmed with simple linear regressions reported in Table 1; the negative association of output growth following exits with the duration of pegged exchange rate spells is significant at $5 \%$ for the full sample and at better than $1 \%$ for the disorderly sample. The table also reports the results of restricting the sample to 1990 or later. Observe that for the sample of both orderly and disorderly exit episodes the negative effect of duration is almost double in magnitude when the 1980s observations are excluded. In contrast, the results for the disorderly exit episodes alone are roughly the same across periods. This implies that orderly exits from longer duration pegs have been associated with more severe output declines in the 1990s than in the 1980s. ${ }^{4}$ One possible reason for this is the greater role of international capital flows.

These results support the findings of Eichengreen and Masson (1998) and Eichengreen (1999) that exits from pegged exchange rate regimes have been accompanied by output declines. In addition, they show that exits from long-lasting pegs, both orderly and disorderly, appear to be accompanied by particularly large falls in economic activity. We proceed to formulate a model that explains these stylized facts.

\section{Model}

The basic framework follows Flood and Marion (1999), a simplified version of Obstfeld (1996)'s model of a small open economy. Output is determined by inflation surprises and real shocks:

$$
y=\pi-\pi^{e}-u
$$

where $\pi, \pi^{e}$ are actual and expected inflation, respectively -- equivalent to the rate of domestic currency devaluation for a small open economy in which purchasing power parity holds, and $u$ is an adverse productivity shock, $u \sim f\left(0, \sigma_{u}^{2}\right) .{ }^{5}$ The social loss function attaches a penalty to inflation (or deflation), deviations of output from a target, and any realignment of the exchange rate:

Unreported regressions confirm this.

The natural rate of output is implicitly set to zero. 


$$
L=\beta_{p} \pi^{2}+(y-k)^{2}+\chi c
$$

where $k(>0)$ is the target level of output associated with distortions in the economy, $\beta_{p}$ is the relative weight placed by the public on inflation/output losses, i.e. its degree of desired firmness against inflation, $\chi$ is the indicator function,

$$
\chi=\left\{\begin{array}{l}
1 \text { if } \pi \neq 0 \\
0 \text { if } \pi=0
\end{array},\right.
$$

and $c$ is the fixed cost associated with any exchange rate realignment.

Policy control is delegated to a monetary authority with the following loss function

$$
M=\beta \pi^{2}+(y-k)^{2}+\chi c,
$$

where the authority's inflation/output loss weight or firmness $\beta$ differs in general from that of society $\beta_{p}$. We assume that $\beta$ is publically known. We deal with the case in which the equilibrium is time invariant and omit time subscipts.

\subsection{Optimal Monetary and Exchange Rate Policy}

The monetary authority optimizes by setting the inflation rate -- and the corresponding devaluation or revaluation rate -- that minimizes the expectation of the loss function (1'). As in similar models, the productivity shock and public's expected inflation rate are known by the monetary authority before choosing the level of inflation, while productivity and the inflation rate are not ex ante known by the public. This leads to a trigger rule, conditional on the authority's anti-inflation firmness $\beta$ :

$$
\pi=\left\{\begin{array}{ccc}
\frac{k+\pi^{e}+u}{1+\beta} & \text { if } & u>\bar{u} \text { or } \underline{u}>u \\
0 & \text { if } & \bar{u}>u>\underline{u}
\end{array}\right.
$$

where

$$
\begin{aligned}
& \bar{u} \equiv \sqrt{c(1+\beta)}-k-\pi^{e} \\
& \underline{u} \equiv-\sqrt{c(1+\beta)}-k-\pi^{e} .
\end{aligned}
$$

The monetary authority's ex post loss from fixing or changing the exchange rate, respectively, is 


$$
\begin{aligned}
& M_{\beta}^{f i x}=\left(k+\pi^{e}+u\right)^{2} \\
& M_{\beta}^{\text {dev }}=\beta\left(\frac{k+\pi^{e}+u}{1+\beta}\right)^{2}+\left(\frac{k+\pi^{e}+u}{1+\beta}-\left(k+\pi^{e}+u\right)\right)^{2}+c=\frac{\beta}{1+\beta}\left(k+\pi^{e}+u\right)^{2}+c
\end{aligned}
$$

where the latter is conditional on the regime's firmness $\beta$. Thus, the authority changes the exchange rate only when $u$ is high enough, i.e. $u>\bar{u}$ (in which case the currency is devalued) or low enough, i.e. $u<\underline{u}_{\beta}$ (in which case the currency is revalued), to make $M_{\beta}^{d e v}<M_{\beta}^{f i x}$. ${ }^{6}$ For shock realizations $\bar{u}>u>\underline{u}$, the fixed exchange rate is maintained.

The expected social loss function corresponding to the optimal inflation rate, given public inflation expectations $\pi^{e}$, and public's anti-inflation weight $\beta_{p}$, is

$$
\begin{aligned}
E(L)=\int_{\underline{u}}^{\bar{u}}\left(k+\pi^{e}+u\right)^{2} f(u) d u+\int_{\bar{u}}^{\infty}\left\{\left(k+\pi^{e}+u\right)^{2} \frac{\beta_{p}+\beta^{2}}{(1+\beta)^{2}}+c\right\} f(u) d u \\
\left.+\int_{-\infty}^{\underline{u}\left\{\left(k+\pi^{e}+u\right)^{2}\right.} \frac{\beta_{p}+\beta^{2}}{(1+\beta)^{2}}+c\right\} f(u) d u
\end{aligned}
$$

As is well known, because expected inflation $\pi^{e}$ enters here both in (i) determining the inflation rate the authority chooses conditional on preferring to realign and in (ii) determining the probability of realignment (through $\bar{u}, \underline{u}$ ), the possibility of multiple equilibria arises. Rational expectation equilibrium implies that public sector's expected inflation $\pi^{e}$ equals the expectation of inflation $E(\pi)$, where

$$
E(\pi)=\int_{-\infty}^{u} \frac{k+\pi^{e}+u}{1+\beta} f(u) d u+\int_{\bar{u}}^{\infty} \frac{k+\pi^{e}+u}{1+\beta} f(u) d u
$$

To gain further insight, let us consider the case where $u$ follows the double exponential distribution, with zero mean and variance $2 / \theta^{2}$ :

$$
f(u)=\frac{\theta}{2} \exp [-\theta|u|]
$$

A convenient feature of this distribution is that we can solve for the closed form of (5): ${ }^{7}$

\footnotetext{
$6 \quad$ The assumption that the costs of realignment $c$ are the same for devaluations or revaluations implies that adjustment is symmetric.

Obstfeld (1996) assumes $u$ is uniformly distributed; Flood and Marion (1999) show how the results are affected by using a normal distribution, with fatter tails than the uniform, implying extreme shocks are more likely to occur. Our assumption of a double exponential permits a tractable analytical solution for a (relatively) fat-tailed distribution.
} 
(7)

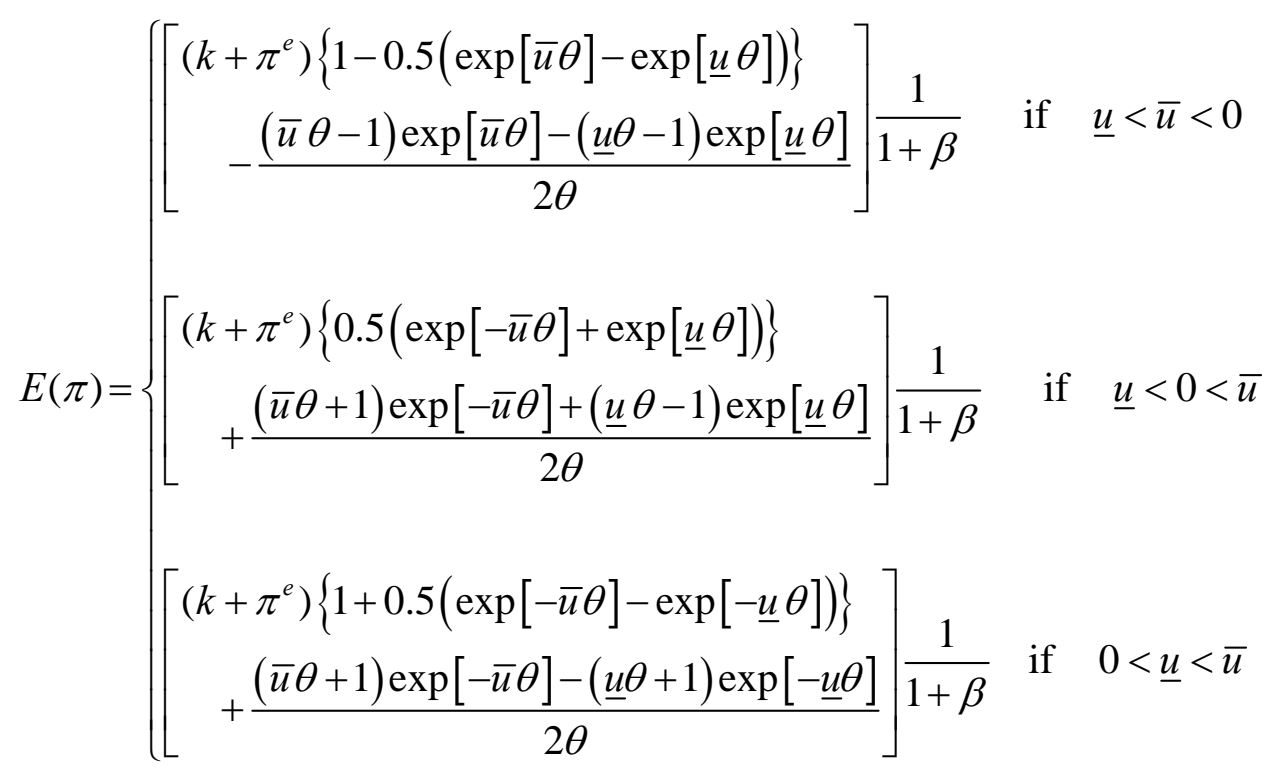

The full equilibrium in which $E(\pi)=\pi^{e}$ is summarized by Figure 4, which graphs expression (7) as an S-shaped curve for different values of $\beta$, together with a $45^{\circ}$ line, assuming the parameter values $c=0.06, k=0.1, \theta=8$. The firmness of the policymaker $\beta$ plays a key role in determining the equilibrium. For "tough" regimes (i.e. high $\beta$ ), there is a unique equilibrium, associated with low expected inflation (e.g. about 5 percent, as at point A for $\beta=0.3$ ). For "soft" regimes (i.e. low $\beta$ ), we have a unique equilibrium associated with high inflation (e.g. about 100 percent, as at point $\mathrm{B}$ for $\beta=0.1$ ). For intermediate regimes, we have multiple equilibria, with 2 or 3 possible inflation rates (Figure 4 depicts the case where for $\beta=0.2$ there are 3 possible equilibrium inflation rates -- $\left.\mathrm{C}_{1}, \mathrm{C}_{2}, \mathrm{C}_{3}\right)$.

In the Appendix we show that for $\beta$ close to $\beta_{p}$ the multiple equilibria in Figure 4 can be Pareto ranked by the level of expected inflation by proving the following claim:

Claim 1: Expected social loss $E(L)$ rises with expected inflation $\pi^{e}$

Assuming that the multiple equilibria occur with equal probability, it follows that the association between the firmness of the regime and expected inflation is discontinuous in the intermediate 
range of firmness, and that the move from the multiple equilibrium range to a unique equilibrium of low inflation is associated with a large drop in expected inflation.

For example, for the parameters used in Figure 4, the minimal level of firmness associated with a unique low inflation equilibrium is about $\beta=0.25$. (The corresponding Sshaped curve - not shown -- would just "kiss" the $45^{\circ}$ line from below between points C1 and C2.) For a firmness level somewhat above 0.25 , the expected inflation is about $5.5 \%$, whereas for a firmness level marginally below that level, multiple equilibria emerge and the expected inflation jumps above 30\%. Lower firmness shifts the curve upward, increasing expected inflation. As noted above, for a low enough firmness level, a unique high inflation equilibrium arises. For $\beta=0.1$, for example, the unique high inflation equilibrium (at point $\mathrm{B}$ ) is associated with expected inflation of roughly $100 \%$.

This discontinuity implies that there are large potential gains from eliminating the multiple equilibria and is the key for the analysis in the paper. It implies that it is desirable to bias the choice of the monetary authority's firmness towards the conservative end of the available pool, not only in order to mitigate the inflation bias arising from time inconsistency, but also to eliminate the excessive expected inflation due to multiple equilibria. Achieving these gains requires picking a monetary authority with a sufficiently high firmness level and hence conservative bias. Such a bias, however, comes also with costs in the form of a lesser responsiveness by the authority to shocks. Hence, there is a trade off between the ex-ante gains from stabilizing expectations and the ex-post costs associated with having a conservative decision maker who is unwilling to allow the exchange rate to adjust in response to very large shocks.

\subsection{Costly Regime Change}

We complete the model by assuming that ex-post the public has the costly option of replacing the existing monetary regime with one representing the public's preferences, i.e. a monetary authority characterized by $\beta=\beta_{p}$. We denote the cost of regime change by $c_{r c}$ and assume $^{8}$

\footnotetext{
${ }^{8}$ It will be shown that this condition implies a non-empty range of discretionary devaluations by the conservative policymaker.
} 
(8) $\frac{c_{r c}}{c}>\frac{\left(\beta-\beta_{p}\right)^{2}}{(1+\beta)\left(1+\beta_{p}\right)}$,

implying the relative cost of regime change exceeds the relative firmness bias of the existing monetary authority. It follows that the inflation rate observed with a monetary authority of type $\beta$ is

(9)

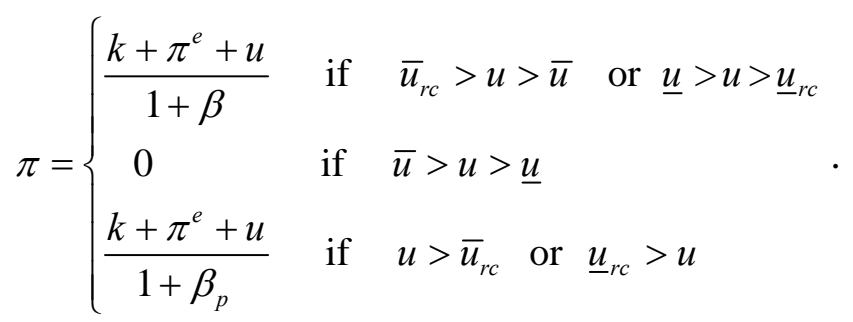

where

$$
\begin{array}{ll}
\bar{u}_{r c} \equiv\left(\frac{1+\beta}{\beta-\beta_{p}}\right) \sqrt{c_{r c}\left(1+\beta_{p}\right)}-k-\pi^{e} ; & \underline{u}_{r c} \equiv-\left(\frac{1+\beta}{\beta-\beta_{p}}\right) \sqrt{c_{r c}\left(1+\beta_{p}\right)}-k-\pi^{e} \\
\bar{u} \equiv \sqrt{c(1+\beta)}-k-\pi^{e} ; & \underline{u} \equiv-\sqrt{c(1+\beta)}-k-\pi^{e}
\end{array}
$$

A monetary authority of type $\beta$ leaves the exchange rate unchanged for shocks in the range $\bar{u}>u>\underline{u}$. The regime remains in place when $u$ is higher, but not "too" high, i.e. $\bar{u}_{r c}>u>\bar{u}$ (in which case the currency is devalued) or low enough, but not "too" low, i.e. $\underline{u}>u>\underline{u}_{r c}$ (in which case the currency is revalued). In these ranges the authority will devalue (or revalue) by an amount $\pi=\frac{k+\pi^{e}+u}{1+\beta}$. For very large shocks, however, i.e. $u>\bar{u}_{r c}$ or $\underline{u}_{r c}>u$, it is socially optimal to replace the regime as well as realign the exchange rate by setting $\pi_{r c}=\frac{k+\pi^{e}+u}{1+\beta_{p}}$, which is larger than $\pi$ since $\beta>\beta_{p}{ }^{9}$

$9 \quad$ The expected depreciation rate that prevails in the event of regime change is the same as under a completely flexible exchange rate. 
To understand this behavior, we compare the ex post social loss function (2) for the cases of no devaluation ( $L^{f i x}$ ), devaluation by a policymaker of firmness type $\beta\left(L_{\beta}^{d e v}\right)$, and a regime change and devaluation set by a (new) policymaker of firmness type $\beta_{p}\left(L_{\beta_{p}}^{r c}\right)$ :

$$
\begin{aligned}
L^{f i x} & =\left(k+\pi^{e}+u\right)^{2} \\
L_{\beta}^{d e v} & =\beta_{p}\left(\frac{k+\pi^{e}+u}{1+\beta}\right)^{2}+\left(\frac{k+\pi^{e}+u}{1+\beta}-\left(k+\pi^{e}+u\right)\right)^{2}+c \\
& =\frac{\beta_{p}+\beta^{2}}{(1+\beta)^{2}}\left(k+\pi^{e}+u\right)^{2}+c \\
L_{\beta_{p}}^{r c} & =\beta_{p}\left(\frac{k+\pi^{e}+u}{1+\beta_{p}}\right)^{2}+\left(\frac{k+\pi^{e}+u}{1+\beta_{p}}-\left(k+\pi^{e}+u\right)\right)^{2}+c+c_{r c} \\
& =\frac{\beta_{p}}{1+\beta_{p}}\left(k+\pi^{e}+u\right)^{2}+c+c_{r c}
\end{aligned}
$$

Applying (3), the existing monetary authority will not devalue for $u$ shocks in the range $\bar{u}>u>\underline{u}$, since $M_{\beta}^{d e v}>M^{f i x}$. We can also show for shocks in this range that the public will not prefer a regime change because the welfare loss of doing so is less than that of maintaining the regime and leaving the exchange rate unchanged, i.e. $L_{\beta_{p}}^{r c}>L^{f i x}$.

To demonstrate this, note from (10) that $L_{\beta_{p}}^{r c}>L^{f i x}$ implies

$$
\frac{\beta_{p}}{1+\beta_{p}}\left(k+\pi^{e}+u\right)^{2}+c+c_{r c}>\left(k+\pi^{e}+u\right)^{2},
$$

or equivalently,

$$
c+c_{r c}>\frac{1}{1+\beta_{p}}\left(k+\pi^{e}+u\right)^{2} .
$$

However, the definitions of $\bar{u}, \underline{u}$ imply

$$
-c(1+\beta)<\left(k+\pi^{e}+u\right)^{2}<c(1+\beta),
$$

which combined with (8) implies (11) holds. Thus for $\bar{u}>u>\underline{u}$, the existing monetary authority remains in place and no devaluation occurs. 
Suppose now that $u$ is large enough (in absolute value) to induce the policymaker to adjust the exchange rate, but not large enough to prompt a change in regime, e.g. $\bar{u}_{r c}>u>\bar{u}$. The resultant rate of devaluation is

$$
\pi=\frac{k+\pi^{e}+u}{1+\beta}
$$

implying a social welfare loss of $L_{\beta}^{d e v}<L^{f i x}$. In this case the public would continue to support the existing regime as long as the magnitude of devaluation chosen by the policymaker, given by (12), is not viewed as "too timid" a response to the shock and/or if the cost of regime change is not too high, i.e. $L_{\beta}^{\text {dev }}<L_{\beta_{p}}^{r c}$.

To demonstrate this, note that a regime change would entail a devaluation of magnitude

$$
\pi_{r c}=\frac{k+\pi^{e}+u}{1+\beta_{p}}
$$

and a welfare loss of $L_{\beta_{p}}^{r c}$. Thus, the existing regime is maintained if $L_{\beta_{p}}^{r c}>L_{\beta}^{\text {dev }}$, or applying (10), if

$$
\left(\frac{\beta^{2}+\beta_{p}}{(1+\beta)^{2}}-\frac{\beta_{p}}{1+\beta_{p}}\right)\left(k+\pi^{e}+u\right)^{2}<c_{r c},
$$

or equivalently, if

$$
u<\bar{u}_{r c} \equiv \frac{1+\beta}{\beta-\beta_{p}} \sqrt{c_{r c}\left(1+\beta_{p}\right)}-k-\pi^{e} .{ }^{10}
$$

$10 \quad$ Note that $\frac{\beta^{2}+\beta_{p}}{(1+\beta)^{2}}-\frac{\beta_{p}}{1+\beta_{p}}=\frac{\left(\beta-\beta_{p}\right)^{2}}{(1+\beta)^{2}\left(1+\beta_{p}\right)}$ and condition (8), $\frac{c_{r c}}{c}>\frac{\left(\beta-\beta_{p}\right)^{2}}{(1+\beta)\left(1+\beta_{p}\right)}$, implies $c(1+\beta)<c_{r c}(1+\beta) \frac{(1+\beta)\left(1+\beta_{p}\right)}{\left(\beta-\beta_{p}\right)^{2}}$; hence $\bar{u}_{r c}>\bar{u}$, i.e., there is a non-empty range of discretionary devaluations by the conservative policymaker. Note also that the gap between the public's and the monetary authorities' welfare losses in the event of a devaluation not accompanied by a regime change is proportional to the difference between their respective degree of firmness, since $L_{\beta}^{d e v}-M_{\beta}^{d e v}=\left(\frac{\beta^{2}+\beta_{p}}{(1+\beta)^{2}}-\frac{\beta}{1+\beta}\right)\left(k+\pi_{t}^{e}+u_{t}\right)^{2}=\frac{\beta-\beta_{p}}{1+\beta}\left(k+\pi_{t}^{e}+u_{t}\right)^{2}$. 
Thus for $\bar{u}_{r c}>u>\bar{u}$, the shock $u$ is high enough to induce the policymaker to devalue, but not high enough to prompt a regime change. While the policymaker devalues at a rate that is below the public's desired rate ( $\pi_{r c}>\pi$ since $\beta>\beta_{p}$ ), the shock is not high enough to induce a regime change. This is the down side of the conservative bias: the policymaker is too timid in the use of discretionary policy. Yet, for this range of shocks, the social cost of regime change still exceeds the marginal benefit to implementing a higher devaluation rate. Only when $u>\bar{u}_{r c}$ is a regime change and a greater magnitude of devaluation desirable. A similar analysis holds for $\underline{u}>u>\underline{u}_{r c}$ and $\underline{u}_{r c}>u$.

Figure 5 illustrates the ex-ante gains associated with conservative bias. Analogously to Figure 4, it graphs $E(\pi)=\pi^{e}$ and illustrates the determination of equilibrium expected inflation, for the case where $c=0.1, k=0.1, \theta=7, c_{r c}=0.06, \beta_{p}=0.1$ and the firmness of the monetary authority corresponding to the two S-shaped curves, from top to bottom, is $\beta=0.1,0.2{ }^{11}$ It is easy to confirm that condition (8) is satisfied for these parameters.

The top S-shaped curve corresponds to the case where the monetary authority antiinflation firmness equals the public's anti-inflation preference, i.e. $\beta=\beta_{p}=0.1$. The rational expectations inflation rate is determined by the intersection of the $45^{\circ}$ line and this curve. The outcome in this case is one of multiple equilibria, one of which is a high inflation equilibrium (at point B), with $\pi^{e}=100 \%$. The simulation reveals that the threshold level associated with the switch from multiple equilibria to a unique equilibrium case is (about) $\beta=0.2$ (where the S-curve "kisses" $45^{\circ}$ line from below, as at point C). Note that this switch is associated with a large discontinuous drop in expected inflation. It can be verified that the net effect of switching from a policymaker with firmness level $\beta=\beta_{p}=0.1$ (matching the public's desired firmness level) to a policymaker with $\beta=0.2$ is a large drop in expected social loss, $E[L]$. It is also the case that, as drawn with the S-curve tangent to the $45^{\circ}$, choosing the threshold $\beta=0.2$ with associated inflation at point $\mathrm{A}$ is optimal: further increases in the conservative bias would reduce welfare. 
To understand the determinants of the optimal level of bias, we note that in general, for a given public anti-inflation preference level $\beta_{p}$, the welfare effect of choosing a more conservative monetary authority type can be expressed as

$$
\frac{d E[L]}{d \beta}=\frac{\partial E[L]}{\partial \beta}+\frac{\partial E[L]}{\partial \pi^{e}} \frac{\partial \pi^{e}}{\partial \beta}
$$

The first term of (14) corresponds to the direct welfare effect of greater conservative bias, holding the expected inflation constant. The second term measures the indirect effect of greater conservative bias through changing expected inflation. In the Appendix we show that

Claim 2: For a given level of $\beta_{p}$, (i) $\partial E[L] / \partial \beta>0$, i.e. greater conservative bias increases the expected social loss, holding expected inflation given; (ii) $\left(\partial E[L] / \partial \pi^{e}\right)\left(\partial \pi^{e} / \partial \beta\right)<0$, i.e. greater conservative bias reduces the expected social loss by reducing expected inflation.

That the expected loss rises with a more conservative regime follows from the property that in circumstances leading to exchange rate adjustment, a more conservative decision maker uses discretion more timidly. A more conservative monetary authority has an opposing effect on expected loss by reducing expected inflation. Consequently, the welfare effect of the conservative bias is ambiguous, being the sum of two opposing effects. Choosing the candidate with the conservative bias sufficiently high enough to eliminate the multiple equilibria would be optimal if the drop in expected inflation (captured by the second term) dominates the first. This will be the case if the discrete drop in expected inflation is large enough, as is the situation in Figure 5. The conservative bias comes, however, with potential ex-post costs: the policy maker may be "too conservative" when bad shocks hit the economy. In these circumstances, a very bad state of nature would induce a regime change, and a large discretionary devaluation.

The optimal degree of policy firmness, $\beta^{*}$, corresponds to the point of tangency between the lower S-shaped curve and the $45^{\circ}$ ray (e.g. point $C$ in Figure 5), and is associated with the relatively low expected inflation rate (corresponding to point A ). ${ }^{12}$ The location of the

12 The discontinuity of expected inflation associated with this equilibrium implies that the optimal bias must actually exceed $\beta^{*}$ marginally in order to induce the low inflation equilibrium. More specifically, recall that because of the knife-edge discontinuity in the effect of $\beta$ on expected inflation, for $\beta$ just below the threshold $\beta^{*}$ there are multiple equilibria for expected inflation, while for $\beta$ marginally above $\beta^{*}$ a unique equilibrium with lower 
$E(\pi)=\pi^{e}$ curves and this equilibrium are perturbed by variations in the costs of devaluation $c$ and of regime change, $c_{r c}$. From (7) it follows that a higher cost of devaluation, reduces the range where discretionary devaluations take place, thereby shifting the expected inflation curves downward. A similar result applies for higher costs of regime change, $c_{r c}$. Consequently, a higher cost of regime change or higher cost associated with devaluation each reduce the optimal conservative bias needed to prevent multiple equilibria. That is,

$$
\frac{d \pi^{e}}{d c_{r c}}<0, \frac{d \beta^{*}}{d c_{r c}}<0 ; \quad \frac{d \pi^{e}}{d c}<0, \frac{d \beta^{*}}{d c}<0 .
$$

We can express this relation in reduced form as: $\beta^{*}=\beta^{*}\left[c, c_{r c}\right] ; \partial \beta^{*} / \partial c<0, \partial \beta^{*} / \partial c_{r c}<0$.

We next turn to the effects of the exit from an exchange rate regime on output. The association between the duration of the regime and the magnitude of the output drop following a devaluation triggered by a regime change is summarized by the following:

Claim 3: Consider a pegged exchange rate regime that is maintained until a large enough adverse shock induces a regime change and devaluation. The average output decline associated with the change is larger the longer is the duration of the prior pegged regime.

We prove this claim in several stages. First, we evaluate the factors determining the output decline associated with a shock large enough to lead to regime change. Next, we characterize the factors determining the duration of the peg, and identify the factors impacting both the duration of the peg, and the ultimate cost of the exiting the peg.

Denote by $u_{r c}$ the adverse productivity shock which is large enough to cause a regime change, i.e. $u_{r c}>\bar{u}_{r c}$ (see the discussion after (12)). Applying (12') and the output equation, the resulting regime change is associated with a negative output gap of

$$
y_{r c}-k=\pi_{r c}-\left(k+\pi^{e}+u_{r c}\right)=\frac{k+\pi^{e}+u_{r c}}{1+\beta_{p}}-\left(k+\pi^{e}+u_{r c}\right)=-\frac{\beta_{p}}{1+\beta_{p}}\left(k+\pi^{e}+u_{r c}\right)
$$

expected inflation occurs. This discontinuity also applies to the sign of (14) and the impact of $\beta$ on expected welfare: for $\beta>\beta^{*}\left(\beta<\beta^{*}\right.$ ), the impact of greater conservative bias ( $d E[L] / d \beta$ ) is to reduce (increase) the public loss. 
Since $u_{r c}>\bar{u}_{r c}$, it follows that

$$
y_{r c}-k \leq-\frac{\beta_{p}}{1+\beta_{p}}\left(k+\pi^{e}+\bar{u}_{r c}\right) .
$$

Substituting with the definition of $\bar{u}_{r c}$ from (13') implies that ${ }^{13}$

$$
y_{r c}-k \leq-\frac{\beta_{p}}{1+\beta_{p}} \phi
$$

where $\phi \equiv \frac{1+\beta}{\beta-\beta_{p}} \sqrt{c_{r c}\left(1+\beta_{p}\right)}$.

It can be verified readily that $\frac{d \phi}{d c_{r c}}>0$ and $\frac{d \phi}{d \beta}<0$, implying that a higher cost of regime change $\left(c_{r c}\right)$, or a lower conservative bias $\left(\beta-\beta_{p}\right)$, increase the output gap at the time of the regime change. ${ }^{14}$

Further insight is gained by evaluating the duration of a peg. ${ }^{15}$ Denote the probability of sustaining the peg in each period by

$$
\Gamma=\int_{\underline{u}}^{\bar{u}} f(u) d u
$$

where, recall from (2), the upper and lower bounds of productivity shocks inducing a devaluation are given by

$$
\bar{u} \equiv \sqrt{c(1+\beta)}-k-\pi^{e} ; \quad \underline{u} \equiv-\sqrt{c(1+\beta)}-k-\pi^{e} .
$$

The expected duration of a fixed exchange rate is the probability of sustaining the peg, relative to the probability of leaving the peg, or ${ }^{16}$

13 Note that the response of output and inflation to productivity shocks is discontinuous around the magnitude of $\mathrm{u}$ that triggers a regime change. That is, for $\bar{u}<\bar{u}_{r c} \quad y-k \leq-(\beta /(1+\beta))\left(k+\pi^{e}+u\right)$, while for $u>\bar{u}_{r c}$ the output gap is given by (16).

14 To determine $d \phi / d \beta<0$, note that $\partial\left\{\frac{1+\beta}{\beta-\beta_{p}}\right\} / \partial \beta=-\frac{1+\beta_{p}}{\left(\beta-\beta_{p}\right)^{2}}<0$.

15 There are four possible cases for exiting from the current exchange rate peg: (i) devaluation without regime change, (ii) revaluation without regime change, (iii) devaluation with regime change, and (iv) revaluation with regime change. The following discussion focuses only on the first two cases; analysis of the other cases is analogous. 


$$
\frac{\Gamma}{1-\Gamma}
$$

Recall from (15) that a higher cost of regime change has the effect of reducing the expected inflation $\pi^{e}$ and the optimal conservative bias $\beta^{*}-\beta_{p}$. This implies a higher probability of sustaining the peg (since the range $\bar{u}-\underline{u}$ widens), as well as higher level of $\phi$ (since $d \phi / d c_{r c}>0$ and $\left.d \phi / d \beta<0\right) .{ }^{17} \quad$ Hence, a higher cost of regime change implies, on average, a longer duration of the peg, and greater output costs associated with the change in exchange rate, when a large enough adverse shock occurs.

\section{Concluding Remarks}

In this paper we have presented a simple model in which the conservative bias of an exchange rate/monetary regime as well the cost of changing an exchange rate regime affects the tradeoff between anti-inflation credibility gains and the ultimate welfare losses costs incurred when exiting the peg. In particular, we have shown that greater conservative bias or higher costs of regime change each reduce expected inflation as long as the regime remains in place. However, the output costs are correspondingly higher once a sufficiently large adverse shock prompts an exit from the regime.

This analysis helps understand the explosive ending of many recent pegged exchange rate regimes, such as that of Argentina in 2001. In our framework the legal anchoring of Argentina's currency board regime through the country's constitution can be interpreted as an effort to raise the cost of devaluation and regime change. While this effort provided obvious anti-inflation credibility gains, it also raised the eventual costs of exiting the peg. It apparently prolonged the duration of the peg, but at a cost of greater loss of output upon the ultimate exit from the peg via a regime change. The empirical evidence we present suggests that these tradeoffs have relevance for many countries struggling with the design of exchange rate regimes.

$$
\sum_{j=0}^{\infty} j \Gamma^{j}(1-\Gamma)=(1-\Gamma) \Gamma \sum_{j=0}^{\infty} j \Gamma^{j-1}=(1-\Gamma) \Gamma\left[\sum_{j=1}^{\infty} \Gamma^{j}\right]=(1-\Gamma) \Gamma\left[\frac{\Gamma}{1-\Gamma}\right]=\frac{\Gamma}{1-\Gamma} \cdot
$$

17 The impact of higher devaluation cost c on the duration of the peg is the sum of two opposing forces: (i) a positive effect through lower expected inflation and an increase in $\bar{u}$, and (ii) a negative effect through a lower optimal conservative bias that reduces $\bar{u}$. It can be shown that the first effect dominates, i.e. a higher devaluation cost $\mathrm{c}$ increases the peg duration. A similar result applies for a higher regime change cost. 


\section{References}

Agenor, Richard and Peter Montiel, 1999. Development Macroeconomics, $2^{\text {nd }}$ edition, Princeton Press.

Cukierman, Alex and Liviatan, Nissan, 1991. "Optimal accommodation by strong policymakers under incomplete information, "Journal of Monetary Economics, 27(1), pp. 99-127.

Detragiache,Enrica, Ashoka Mody, and Eisuke Okada, 2005. "Exits from heavily managed exchange rate regimes," IMF WP/05/39.

Eichengreen, B. 1999. "Kicking the habit: moving from pegged rates to greater exchange rate flexibility,” Economic Journal, March, C1-C14.

Eichengreen , Barry, and Paul Masson, 1998. "Exit strategies: Policy options for countries seeking greater exchange rate flexibility,” Occasional Paper No. 98/168 (Washington: International Monetary Fund).

Flood, R. and Marion, N. 1999. "Perspectives on recent currency crisis literature." International Journal of Finance and Economics, Vol 4, No. 1, 1-26.

Husain, M. Aasim., Ashoka Mody and Kenneth S. Rogoff. 2005. "Exchange rate regime durability and performance in developing versus advanced economies," Journal of Monetary Economics, 52 ( 1), pp. 35-64

Klein, Michael W. and Nancy Marion. 1997. "Explaining the duration of exchange-rate pegs,” Journal of Development Economics, 54(2), 387-404.

Lohmann, Susanne. 1992. “The optimal degree of commitment: Credibility and flexibility.” American Economic Review, 82(1), March, 273-286.

Obstfeld, M. 1996. "Models of currency crises with self fulfilling features,” European Economic Review 40, April, 1037-1048.

Obstfeld, M. and K. Rogoff, 1996. Foundations of International Economics, MIT Press.

Rogoff, K. 1985. “The optimal degree of commitment to an intermediate monetary target," Quarterly Journal of Economics, 1169-89.

Reinhart, Carmen, and Kenneth Rogoff, 2004, "The modern history of exchange rate arrangements: A reinterpretation,” Quarterly Journal of Economics, Vol. 119, No. 1, pp. $1-48$. 


\section{Appendix}

\section{A. Claim 1: Expected social welfare loss increases with expected inflation, for $-k<\pi^{e}$ :}

Proof: Equation (4) and the envelope theorem imply that for $\beta$ close to $\beta_{p}$

$$
\frac{\partial E(L)}{d \pi^{e}} \cong 2 \int_{-\infty}^{\infty} y(u) f(u) d u
$$

where

$$
y(u)= \begin{cases}\left(k+\pi^{e}+u\right) \frac{\beta_{p}+\beta^{2}}{(1+\beta)^{2}} & \text { for } \bar{u}<u \\ k+\pi^{e}+u & \text { for } \underline{u}<u<\bar{u} . \\ \left(k+\pi^{e}+u\right) \frac{\beta_{p}+\beta^{2}}{(1+\beta)^{2}} & \text { for } u<\underline{u}\end{cases}
$$

and $\underline{u}, \bar{u}$ are defined by (2). Inspection of (A2) reveals that $y(u)$ is a piece-wise linear function; and $|y(u)|$ is a symmetric function of $u$ around $\pi^{e}=-k$. Recall that $f(u)$ is symmetric around $u=0$. Hence,

(A3) for $\pi^{e}=-k, \frac{\partial E(L)}{\partial \pi^{e}}=0$.

Note also that $\frac{\partial^{2} E(L)}{\partial\left[\pi^{e}\right]^{2}}>0$. Consequently, the expected loss function is minimized at $\pi^{e}=-k$, and for $\pi^{e}>-k$, higher expected inflation increases the expected loss function.

B. Claim 2: (i) $\partial E[L] / \partial \beta>0$, (ii) $\left(\partial E[L] / \partial \pi^{e}\right)\left(\partial \pi^{e} / \partial \beta\right)<0$

Proof: Recall the definitions of $L^{f i x}, L_{\beta}^{d e v}, L_{\beta_{p}}^{r c}$ in (10) for the social loss in the absence of no devaluation, devaluation by a policy maker of type $\beta$, and regime change followed by devaluation set by a policymaker of type $\beta_{p}$, respectively. The expected social loss is

(B1) $E[L]=\int_{-\infty}^{\underline{u}_{r c}} L_{\beta_{p}}^{r c} f(u) d u+\int_{\underline{u}_{r c}}^{\underline{u}} L_{\beta}^{d e v} f(u) d u+\int_{\underline{u}}^{\bar{u}} L^{f i x} f(u) d u+\int_{\bar{u}}^{\bar{u}_{r e}} L_{\beta}^{d e v} f(u) d u+\int_{\bar{u}_{r c}}^{\infty} L_{\beta_{p}}^{r c} f(u) d u$

Applying the envelope theorem, it follows that increasing the conservative bias affects the expected loss function by the sum of two terms, reflecting the direct effect of greater bias and the indirect effect through inflation expectations, respectively: 
(B2)

$$
\frac{d E[L]}{d \beta}=\frac{\partial E[L]}{\partial \beta}+\frac{\partial E[L]}{\partial \pi^{e}} \frac{\partial \pi^{e}}{\partial \beta}
$$

The first term is given by

$$
\begin{gathered}
\frac{\partial E[L]}{\partial \beta}=2\left(\int_{\bar{u}}^{\bar{u}_{r c}}\left(k+\pi^{e}+u\right)^{2} f(u) d u+\int_{\underline{u}_{r c}}^{u}\left(k+\pi^{e}+u\right)^{2} f(u) d u\right) \frac{\beta-\beta_{p}}{(1+\beta)^{3}} . \\
+\frac{1}{2} \sqrt{c(1+\beta)} c \frac{\beta-\beta_{p}}{(1+\beta)^{2}}(f(\bar{u})+f(\underline{u}))>0
\end{gathered}
$$

Hence $\frac{\partial E[L]}{\partial \beta}>0$, implying that increasing the conservative bias reduces the actual exchange rate adjustment in the range where the policymaker would devalue (or revalue), thereby reducing social welfare.

In order to sign the second term, the impact of $\beta$ on welfare through changing expectations, note that for $\beta$ close to $\beta_{p}$

$$
\begin{aligned}
& \frac{\partial E[L]}{\partial \pi^{e}}=2 \int_{\underline{u}}^{\bar{u}}\left(k+\pi^{e}+u\right) f(u) d u+2 \int_{\bar{u}}^{\bar{u}_{r c}} \frac{\beta^{2}+\beta_{p}}{(1+\beta)^{2}}\left(k+\pi^{e}+u\right) f(u) d u \\
& +2 \int_{\underline{u}_{r c}}^{u} \frac{\beta^{2}+\beta_{p}}{(1+\beta)^{2}}\left(k+\pi^{e}+u\right) f(u) d u+2 \int_{\bar{u}^{r c}}^{\infty} \frac{\beta_{p}}{1+\beta_{p}}\left(k+\pi^{e}+u\right) f(u) d u \\
& +2 \int_{-\infty}^{\underline{u}_{r c}} \frac{\beta_{p}}{1+\beta_{p}}\left(k+\pi^{e}+u\right) f(u) d u>2 \frac{\beta_{p}}{1+\beta_{p}} \int_{-\infty}^{\infty}\left(k+\pi^{e}+u\right) f(u) d u=2 \frac{\beta_{p}}{1+\beta_{p}}\left(k+\pi^{e}\right)>0
\end{aligned}
$$

Hence, higher expected inflation is welfare reducing:

$$
\frac{\partial E[L]}{\partial \pi^{e}}>0
$$

Consequently, since higher $\beta$ reduces expected inflation (i.e. $\frac{\partial \pi^{e}}{\partial \beta}<0$ ), the lower expected inflation induced by a greater conservative bias is welfare enhancing:

$$
\frac{\partial E[L]}{\partial \pi^{e}} \frac{\partial \pi^{e}}{\partial \beta}<0
$$

The effect of greater bias depends on the sum of the effects reported by (B3) and (B4) [see (B2)]. 
Table 1. Output Growth and Duration of Pegged Regime

\begin{tabular}{|c|c|c|c|c|}
\hline & \multicolumn{2}{|c|}{$1980-2001$} & \multicolumn{2}{|c|}{$1990-2001$} \\
\hline & $\begin{array}{c}\text { All } \\
\text { Exits }\end{array}$ & $\begin{array}{l}\text { Disorderly } \\
\text { Exits }\end{array}$ & $\begin{array}{c}\text { All } \\
\text { Exits }\end{array}$ & $\begin{array}{l}\text { Disorderly } \\
\text { Exits }\end{array}$ \\
\hline Duration & $\begin{array}{c}-0.0061^{\star \star} \\
(0.0030) \\
{[0.044]}\end{array}$ & $\begin{array}{c}-0.0172^{\star \star \star} \\
(0.0044) \\
{[0.000]}\end{array}$ & $\begin{array}{c}-0.0108^{\star *} \\
(0.0041) \\
{[0.014]}\end{array}$ & $\begin{array}{c}-0.0158^{\star \star \star} \\
(0.0052) \\
{[0.008]}\end{array}$ \\
\hline constant & $\begin{array}{r}0.1465 \\
(0.8012) \\
{[0.856]}\end{array}$ & $\begin{array}{r}-0.6770 \\
(1.1067) \\
{[0.612]}\end{array}$ & $\begin{array}{r}0.6454 \\
(0.9974) \\
{[0.523]}\end{array}$ & $\begin{array}{r}-0.6567 \\
(1.4693) \\
{[0.661]}\end{array}$ \\
\hline \# of exit obs. & 62 & 32 & 32 & 18 \\
\hline R2 & 0.0707 & 0.273 & 0.174 & 0.280 \\
\hline
\end{tabular}

Notes: OLS estimates. Robust standard errors in parentheses; $p$-values in brackets. ${ }^{* \star \star}$ indicates significance at $1 \%,{ }^{\star \star}$ at $5 \%$. Dependent variable is minimum of output growth (in percent) in year of exit or year following. Explanatory variable is duration (in months) of exchange rate peg in effect prior to exit. 
Figure 1. Real Output Growth during Exits from Pegged Exchange Rate Regimes 1980-2001

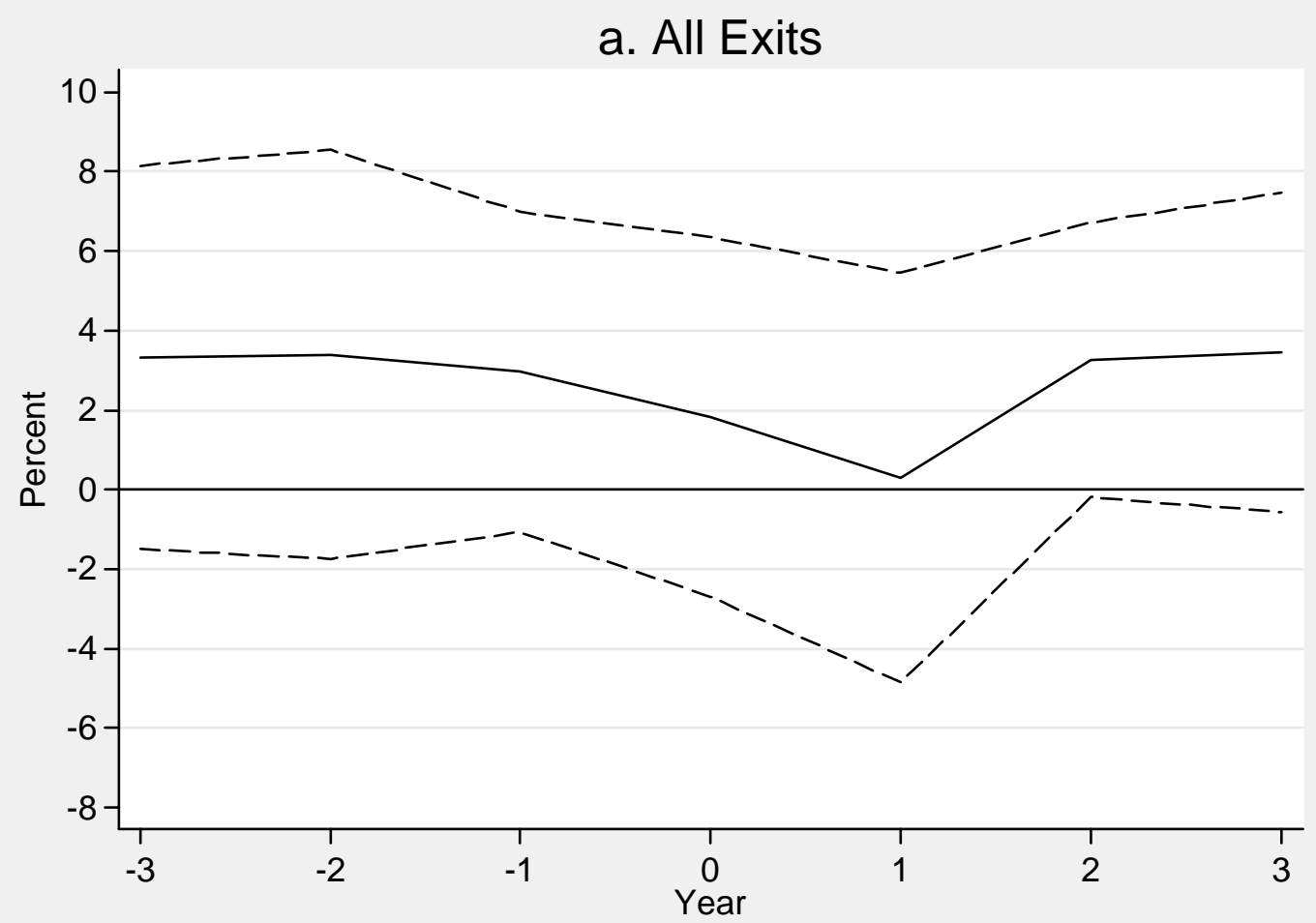

b. Disorderly Exits

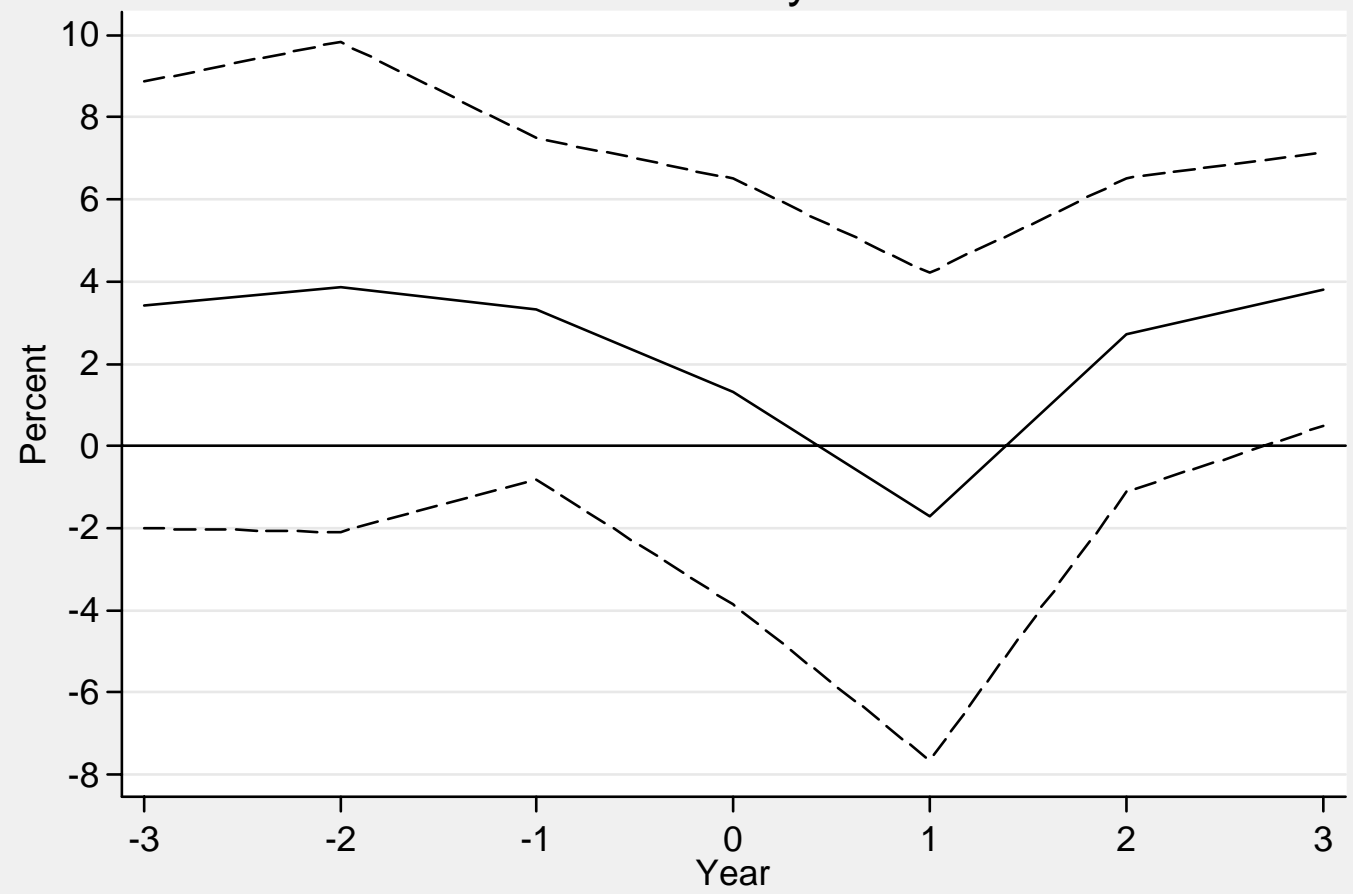

Note: Figures are centered on the year of exit, with two standard deviation bands. 
Figure 2. Real Output Growth during Exits from Pegged Exchange Rate Regimes 1990-2001

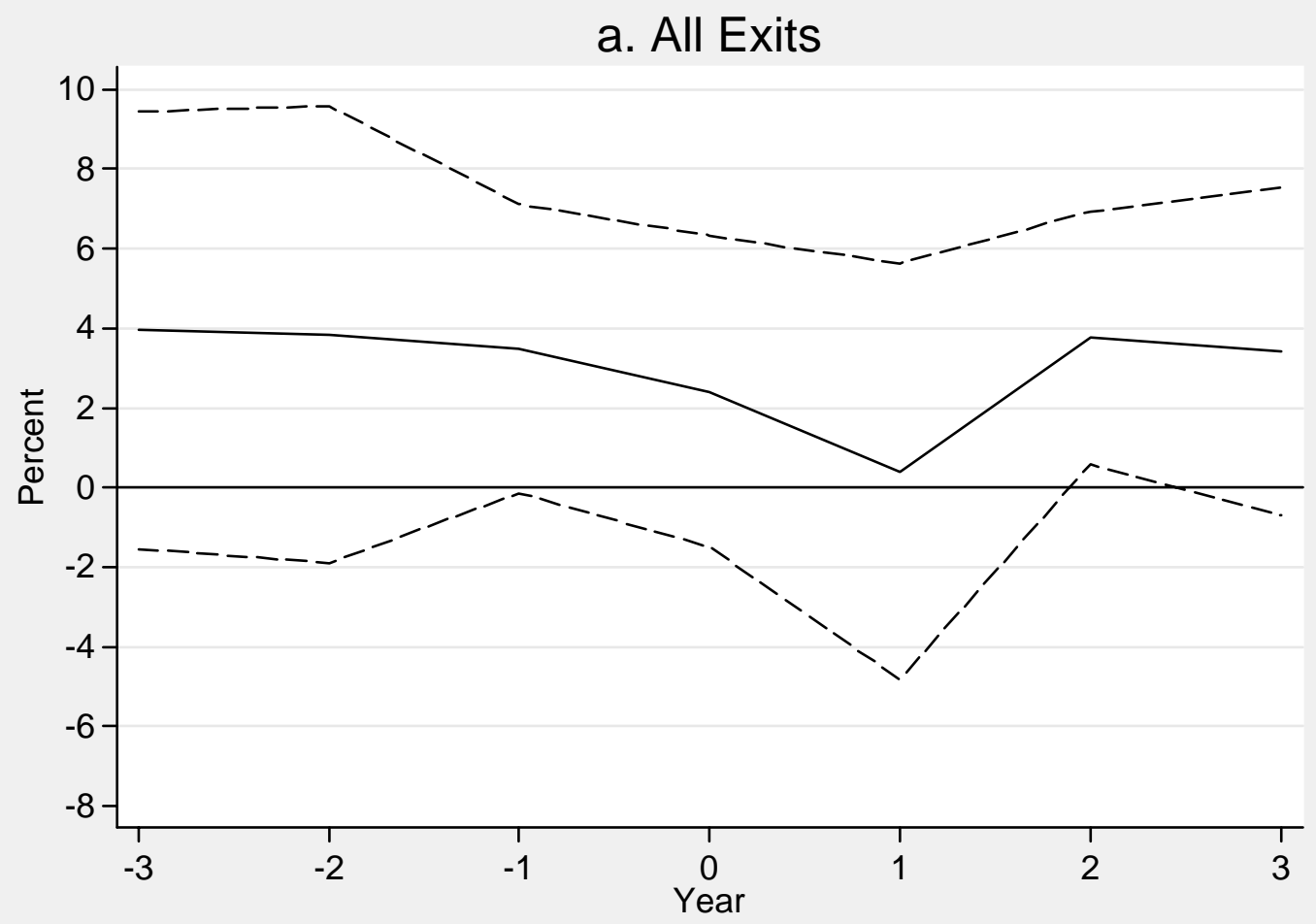

b. Disorderly Exits

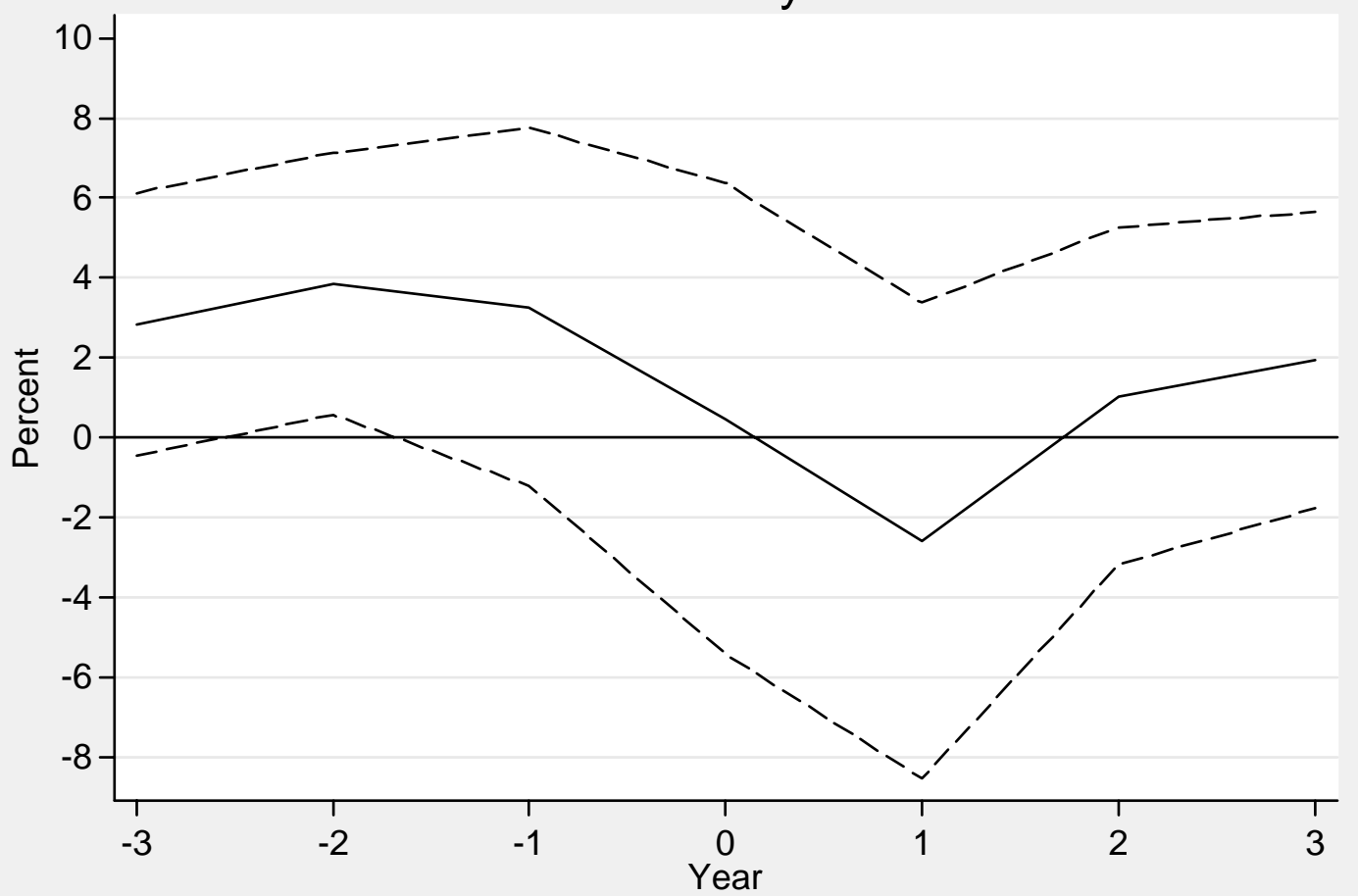

Note: Figures are centered on the year of exit, with two standard deviation bands. 
Figure 3. Scatterplot of Real Output Growth after Exit against Peg Duration
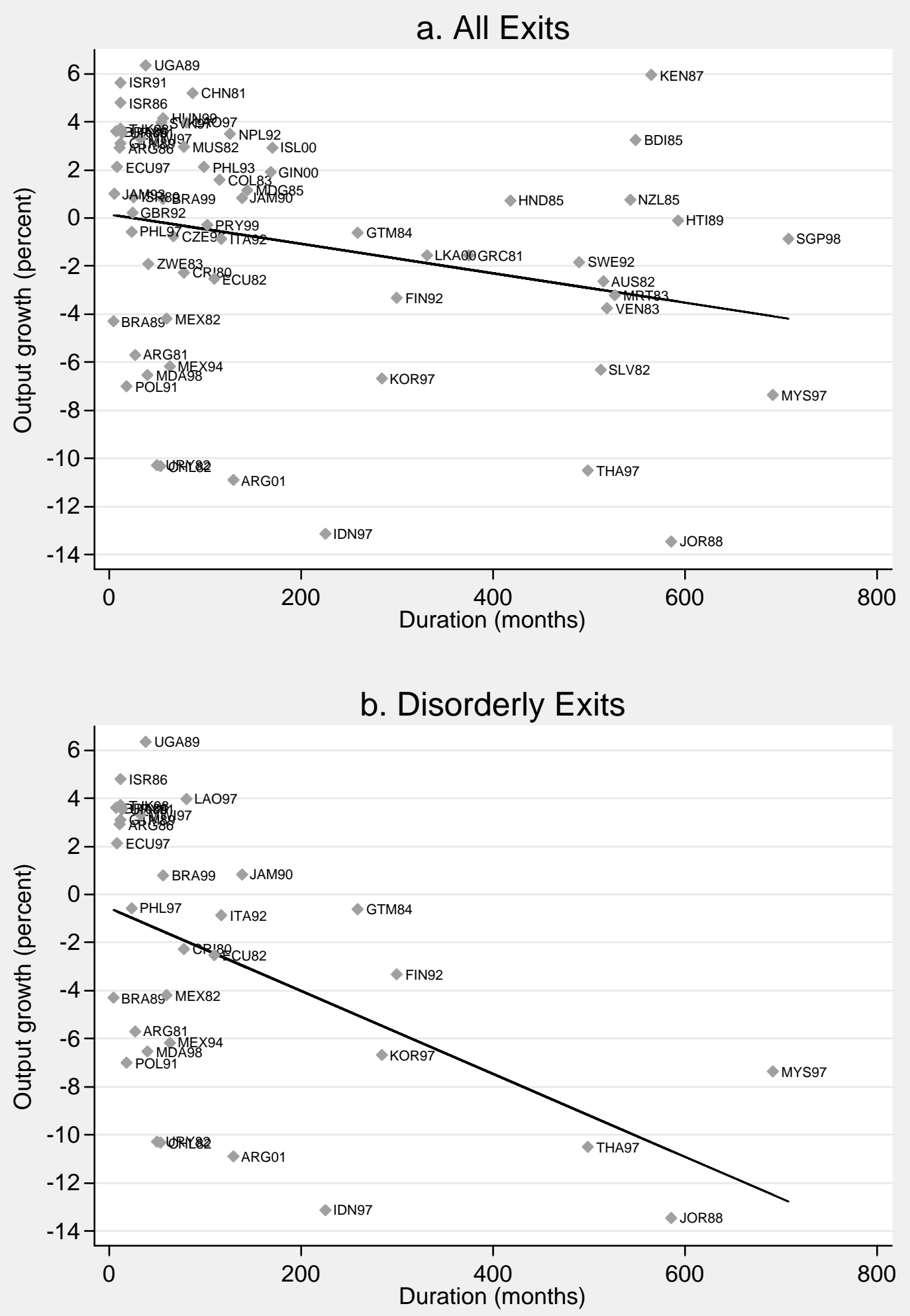

Note: Output growth defined as lower of growth in exit year or subsequent year. 
Figure 4. Expected Inflation and Multiple Equilibria, with Costly Devaluation $E(\pi)$

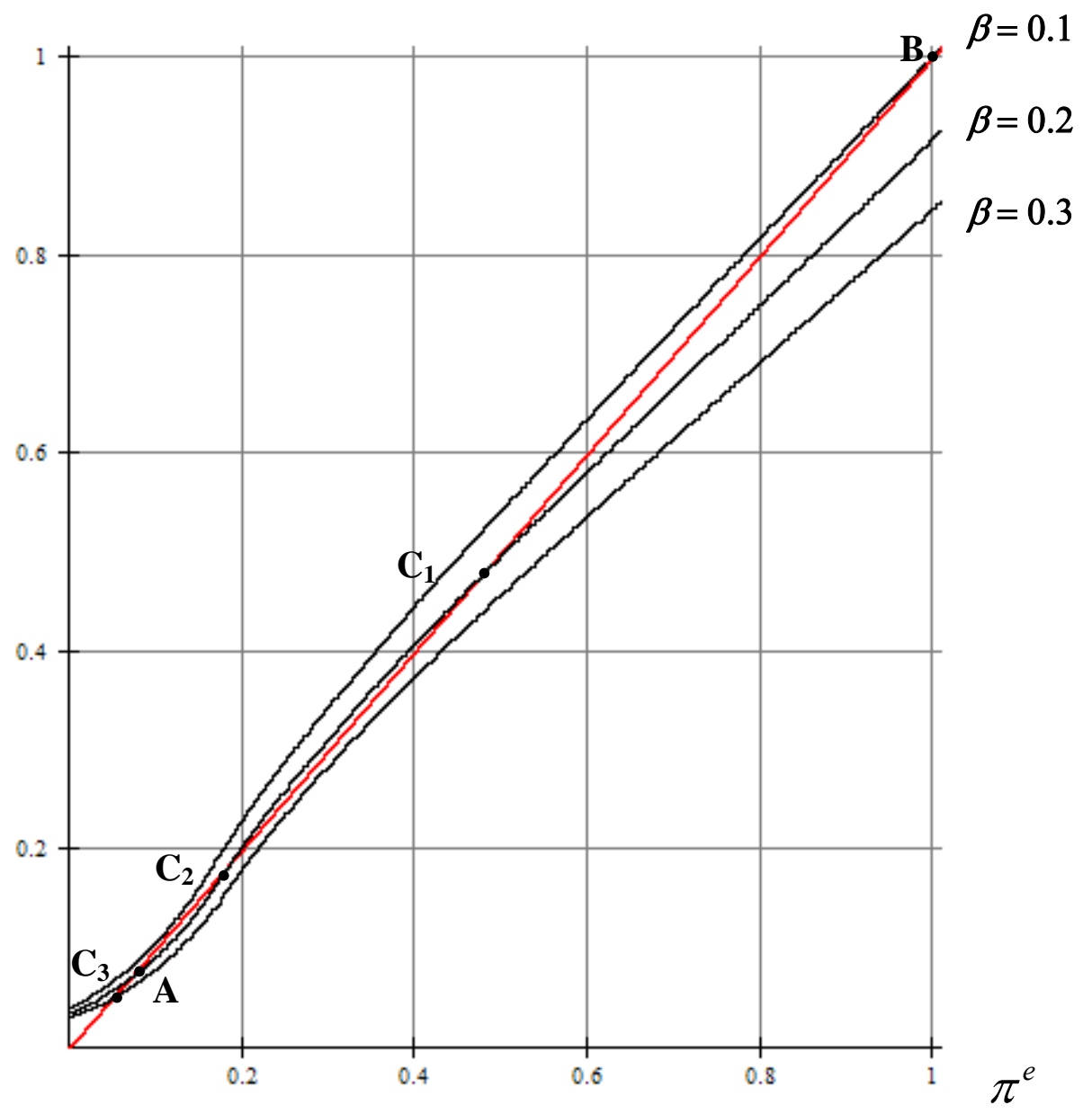

Note: Plotted curves correspond (from top to bottom) to anti-inflation firmness levels of $\beta=0.1,0.2,0.3$, respectively, for $c=0.06, k=0.1, \theta=8$. The straight solid line from the origin is the 45 degree ray. 
Figure 5. Expected Inflation and Multiple Equilibria, with Costly Regime Change

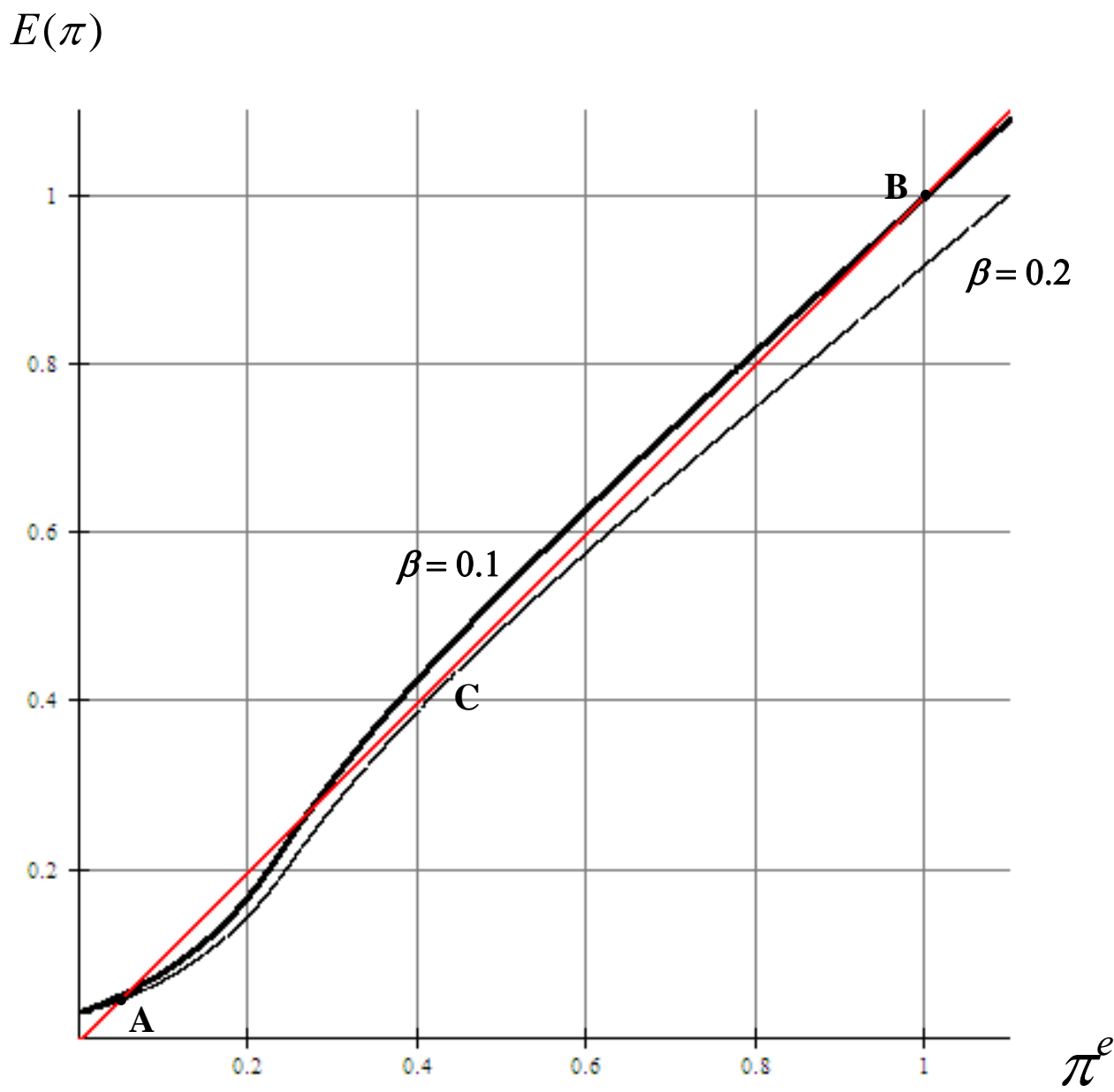

Notes: Plotted curves assume $\beta_{p}=0.1, c_{r c}=0.06, c=0.1, k=0.1, \theta=7$. The top bolded curve determines expected inflation for a monetary authority with firmness $\beta=\beta_{p}=0.1$. The bottom curve determines expected inflation for an authority with firmness $\beta=0.2$ that exceeds the public's preference. The solid straight line from the origin is the 45 degree ray. 